\title{
Hepatitis B Virus Core Antigen Stimulates IL-6 Expression via p38, ERK and NF-kB Pathways in Hepatocytes
}

\author{
Yang-Xia Li $i^{a, b, c}$ Hai-Jing Fu ${ }^{a, b, c}$ Yan-Li Ren ${ }^{a, b, c}$ Ling Zou, ${ }^{a, b, c}$ Shi-Zhen Shen ${ }^{c}$ \\ Ping Chen ${ }^{a, b, c}$ Ting Sun ${ }^{d}$ Chun-Hong Huang ${ }^{a, b, c}$ Zhi Chen ${ }^{a, b, c}$
}

\begin{abstract}
aState Key Laboratory for Diagnosis and Treatment of Infectious Diseases, Institute of Infectious Diseases, First Affiliated Hospital, School of Medicine, Zhejiang University, Hangzhou, 'bCollaborative Innovation Center for Diagnosis and Treatment of Infectious Diseases, Hangzhou, 'School of Medicine, Zhejiang University, Hangzhou, 'Zhejang Provincial People's Hospital, Hangzhou, China
\end{abstract}

\section{Key Words}

Hepatitis B core antigen $\bullet \mathrm{IL}-6 \cdot \mathrm{p} 38 \mathrm{MAPK} \cdot \mathrm{ERK} \cdot \mathrm{NF}-\mathrm{KB}$

\begin{abstract}
Background: Hepatitis B virus (HBV) causes both acute and chronic liver injury. Viral proteins are involved in the pathological progress. Hepatitis B core antigen $(\mathrm{HBCAg})$, a component of viral nucleocapsid, is not only essential for HBV lifecycle, but also exhibits strong immunogenicity. The cytoplasmic location of HBcAg in liver biopsy is associated with liver injury and inflammation, but the exact mechanisms remain to be elaborated. Methods: Huh7, SMMC-7721 and L-02 cells were transfected with pEGFP-N1-HBCAg to establish an intracellular HBcAg expression model. The mRNA and protein levels of Interleukin (IL)- 6 were detected by qPCR and ELISA respectively. The signaling pathway-related proteins were investigated by western blot and immunofluorescence assay. Results: HBcAg increased the expression and secretion of IL-6 through activating extracellular signal-related kinase (ERK), p38 mitogen-activated protein kinase (p38 MAPK) and nuclear factor-kappa B (NF-kB). These activations can be blocked by specific inhibitors of the three pathways. Conclusions: $\mathrm{HBCAg}$ actives p38, ERK1/2 and NF-KB to enhance the production of IL- 6 in hepatocytes. This provides a molecular mechanism to explain the association of cytoplasmic HBcAg with severe liver injury and inflammation.

(C) 2017 The Author(s)

Published by S. Karger AG, Basel
\end{abstract}

\section{Introduction}

Hepatitis B virus (HBV) infection can develop progressive chronic disease that leads to hepatitis, cirrhosis and hepatocellular carcinoma (HCC) [1]. It has been suggested that HBV genotypes and viral components contribute to HBV-related pathogenesis [2], but its molecular mechanisms remain unclear. Hepatitis B core antigen (HBcAg) is not only an important viral structural protein, but also exhibits strong immunogenicity eliciting both humoral and cellular immunoresponse. 
The responses of a HBV-infected host to HBcAg exposure appears to be diverse. HBcAg negatively regulates HBcAg-specific T-helper (Th) 17cell responses [3], inhibits host antiviral immunity through upregulating the expression of programmed death-1 (PD-1) on CD4 ${ }^{+} \mathrm{T}$ cells [4]. On the other hand, HBcAg induced intra-hepatic leukocytes (IHLs) to produce tumor necrosis factor alpha (TNF- $\alpha$ ) which is helpful for virus clearance [5].A positive relationship between HBcAg and hepatic inflammation has been observed. HBcAg can be located in nucleus and/or cytoplasm of cells, the predominant cytoplasmic expression of HBcAg was often accompanied by significant liver injury, and thus it was considered as a potent viral antigen for immune-mediated liver damage in chronic hepatitis B (CHB) [6-8]. In addition, intracellular $\mathrm{HBcAg}$ was reported to be related with the pathogenesis of human fulminant viral hepatitis and severe CHB $[9,10]$.

Interleukin (IL)-6 is one of the most important cytokines involved in hepatic inflammation and liver carcinogenesis in both animal models and patients with liver diseases [11-13]. Serum IL-6 level was positively associated with HCC risk [11] and aspartate aminotransferase (AST) [14], and functioned as a predictive factor of HCC survival [15]. During hepatocarcinogenesis, the autocrine IL-6 in HCC progenitor cells (HcPCs) and hepatic stellate cells (HSCs) was linked with cancer progression $[16,17]$. Several studies reported that human hepatoma cells and hepatic cells also secrete IL-6 after activating nuclear factor-kappa B (NF- $\kappa \mathrm{B}$ ) and a MyD88-dependent signaling pathway, and this activation was regulated by PP2C $\alpha$ in the presence of HBV X protein [18-20].

We have found that extracellular recombinant HBcAg stimulation promoted IL-6 production by peripheral blood mononuclear cells (PBMCs) from CHB patients [3], to further investigate the effect of HBcAg on HBV-infected liver cells, we expressed $\mathrm{HBcAg}$ in hepatocytes, and revealed that HBcAg stimulated IL-6 expression and secretion through the activation of NF- $\mathrm{KB}$, extracellular signal-related kinase (ERK) and p38 mitogen-activated protein kinase (p38 MAPK) in hepatic and hepatoma cells.

\section{Materials and Methods}

\section{Cell culture}

Human hepatic L-02 cells, human hepatoma SMMC-7721 cells and Huh7 cells were grown in DMEM containing $10 \%$ fetal calf serum in an atmosphere of $5 \% \mathrm{CO}_{2}$ at $37^{\circ} \mathrm{C}$. The L-02 cells and SMMC-7721 cells were obtained from Cell Bank of Type Culture Collection of Chinese Academy of Science, Shanghai Institute of Cell Biology, Chinese Academy of Science, and Huh7 cells were from American Type Culture Collection.

DNA constructs and transfection

The expression of HBcAg-GFP fusion protein was constructed by cloning the pre-core/core gene into the pEGFP-N1 vector at Hind III (TAKARA, Japan) and Kpn I (TAKARA, Japan) restriction sites. The forward primer was CCCAAGCTT ATGCAACTTTTTCACCTCTGCCTAATC and the reverser primer was CGGGGTACC CATTGAGGTTCCCGAGATTGAG. The pEGFP-N1 vector that expressed GFP protein was used as a control.

Cells were transfected using Lipofection 3000 reagent (Invitrogen, USA) according to manufacturer's instructions. Briefly, a total of $2.5 \mu \mathrm{g}$ of plasmid was transfected into the settled $8 \times 10^{5}$ cells per well in a 6-well plate. Water was treated as plasmids and transfected into cells to make a mock group. At 12 hours and 24 hours after transfection, cells and culture supernatants were collected for analysis.

ELISA

The collected culture supernatants were centrifuged at 1,000 g for two minutes, and IL- 6 protein in the cleared supernatants were detected by ELISA kits (Lianke, China).

\section{Real-time RT-PCR analysis}

Eastep $^{\mathrm{TM}}$ Universal RNA Extraction Kit (Promega, USA) was used to extract total RNA from the collected cells. PrimeScript ${ }^{\mathrm{m}}$ RT reagent Kit with gDNA Eraser (Perfect Real Time; TAKARA, Japan) was used to synthesize cDNA with $2 \mu$ g of RNA templates. SYBR ${ }^{\circledR}$ Premix Ex Taq ${ }^{\text {mi }}$ II (Tli RNaseH Plus; TAKARA, Japan) was used to quantitatively amplify $2 \mu \mathrm{L}$ of cDNA (ABI7500, USA). The expression of $\beta$-actin was detected to calibrate the expression of IL- 6 among different samples. The same primer sequences for IL- 6 and $\beta$-actin 


\section{Cellular Physiology Cell Physiol Biochem 2017;41:91-100

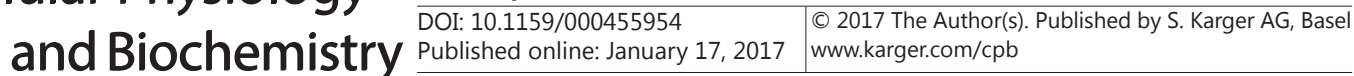

Li et al.: HBcAg Induce IL-6 Synthesis in Hepatocytes

were used, as reported by Xiang et al.[20]. $2^{-\Delta \Delta \mathrm{Ct}}$ method was used to analyze the expression fold change of $I L-6$ mRNA by comparing $\triangle \mathrm{Ct}$ of HBcAg or GFP group to $\triangle \mathrm{Ct}$ of mock group.

Western blot analysis

Cells were collected at 24 hours after transfection, and lyzed with RIPA buffer (Millipore, Germany) to prepare the protein samples. The halt protease and phosphatase inhibitor cocktail (Thermo Scientific, USA) was added to the lysis buffer at a volume ratio of 5:100. After separation in 10\% sodium dodecyl sulfate polyacrylamide gels, proteins were transferred onto polyvinylidene difluoride (PVDF) membranes (Millipore, Germany). PVDF membranes were blocked with 5\% bovine serum albumin (BSA) for two hours at room temperature, incubated with a specific first antibody at a dilution of $1: 1,000$ overnight at $4^{\circ} \mathrm{C}$, followed by incubation with HRP-conjugated secondary antibody $(1: 5,000)$. The first antibodies included antibodies against GFP, p38, phospho-p38, ERK1/2, phospho-ERK1/2 and IкB. All these antibodies were purchased from Cell Signaling (USA). The antibody against GAPDH (Glycerol-3-phosphate dehydrogenase) was supplied by HuaAn Biotechnology (China). An EZ-ECL Kit (Biological Industries, Israel) was used to detect the specific bands. ImageJ software was used to determine the relative levels of targets proteins to GAPDH.

Immunofluorescence assay

Approximately $5 \times 10^{3}$ cells per well were seeded in 24-well plate overnight, transfected with $1 \mu \mathrm{g}$ of plasmids, and incubated for 24 hours. Cells were fixed using 4\% paraformaldehyde for 30 minutes, followed by incubation with $0.5 \%$ Triton-X 100 for 20 minutes at room temperature. After blocking with 1\% BSA, cells were incubated with anti-p65 antibody (Santa Cruz ,USA) or anti- hepatitis B virus core antigen antibody (Abcam, USA) at $4^{\circ} \mathrm{C}$ overnight, incubated with an Alexa Fluor ${ }^{\circledR} 568$ conjugated donkey antiRabbit IgG (H+L) secondary antibody or Alexa Fluor ${ }^{\circledR} 568$ conjugated donkey anti-Mouse IgG secondary antibody (ThermoFisher scientific, USA) for one hour at room temperature, and counterstained by DAPI for five minutes. Subcellular localization of the p65 subunit or HBcAg was examined under Zeiss confocal microscopy (LSM 510 Meta, Germany).

Effect of specific signaling pathway inhibitors on IL-6 stimulation

Approximately $5 \times 10^{4}$ cells per well were cultured in 24 -well plate overnight. At 12 hours after transfection, the transfected cell supernatants were removed and washed with fresh DMEM triplex, incubated with DMEM contained 10\%FBS with the addition of $20 \mu \mathrm{M}$ of SB203580 (Selleck, USA), $15 \mu \mathrm{M}$ of U0126 (Cell Signaling, USA) and $10 \mu \mathrm{M}$ of QNZ (6-amino-4-(4-phenoxyphenylethylamino)quinazoline) (Selleck, USA) individually or mixed for another 12 hours. The supernatants were collected and IL-6 protein levels were detected by ELISA kits (Lianke, China). The high degree of specifity of pyridinyl imidazole SB203580 of MAPK p38 has been determined by researchers, it has no effects on many other protein kinases, including MAPK family members such as ERK1/2 and c-Jun N-terminal kinase (JNK) [21-24]. U0126 inhibit the phosphorylation of ERK1/2 by MPAK kinase 1(MKK1), and its specificity was confirmed by references $[21,25,26]$. QNZ was first discovered by Tobe et al.[27], it may inhibit extracellular $\mathrm{Ca}^{2+}$ influx to disturb the activation of NF- $\mathrm{KB}$ [28], and its specifity was partialy proved by Pratap Karki et al.[29].

\section{Statistical analysis}

SPSS was used to perform statistical analysis (Version 16.0; Chicago, IL, USA). A $p$ - value $<0.05$ was considered statistically significant. The independent $t$-test was used to detect the difference between two groups. A one-way analysis of variance (ANOVA), followed by a Least Significant Difference (LSD) test was used to analyze the difference among three or more groups. The graphs were drawn with GraphPad Prism (Version 5.0; GraphPad, USA) and Adobe Illustrator (Version 6.0; Adobe, USA), datas were presented as mean \pm SME (standard error of the mean).

\section{Results}

IL-6 production in hepatic and hepatoma cells was elevated by HBcAg

The expression of HBcAg was detected by anti-GFP antibody and anti-HBcAg antibody in Huh7 cells (Fig. 1). In Huh7 cells, HBcAg was expressed predominantly in cytoplasm (Fig. 1(a)). IL-6 mRNA and protein expression levels were significantly increased in transfected KARGER 
L-02 cells, SMMC-7721cells and Huh7 cells with a GFP-tagged HBcAg plasmid compared to control plasmid transfected cells. A higher IL-6 expression was more prominent at 24 hours than at 12 hours (Fig. 2( $a$ and b)).

To verify that enhanced IL-6 synthesis was not only occured in HBcAg-overexpressed cells, but also in HBV-replicating cells, we transfected L-02 cells with pcDNA3.0-1.3HBV, and detected the expression of IL-6. Results showed that levels of IL- 6 increased sharply in HBV genomic DNA compared to pcDNA3.0 transfected cells after 24 hours of transfection (Fig. $2(c))$.

\section{p38/ERKs was activated for elevated IL-6 expression by HBcAg}

In order to investigate the signaling pathways possibly involved in HBcAg-induced IL-6 expression, the activity of MAP kinase in L-02, SMMC-7721 and Huh7 cells was probed by specific anti-phospho-p38 and anti-phospho-ERK (Thr202/Tyr204) antibodies. The up-

Fig. 1. Expression of HBcAg in Huh7 cells. (a) The intracellular location of HBcAg was determined by anti-HBcAg antibody using immunofluorescence assay and observed under Zeiss confocal microscopy. The green colour is from GFP, the red colour comes from Alexa Fluor ${ }^{\circledR} 568$, and the blue colour is from DAPI. (b) Proteins from collected cells at 24 hours after transfection were analyzed by western blot using a specific GFP antibody.
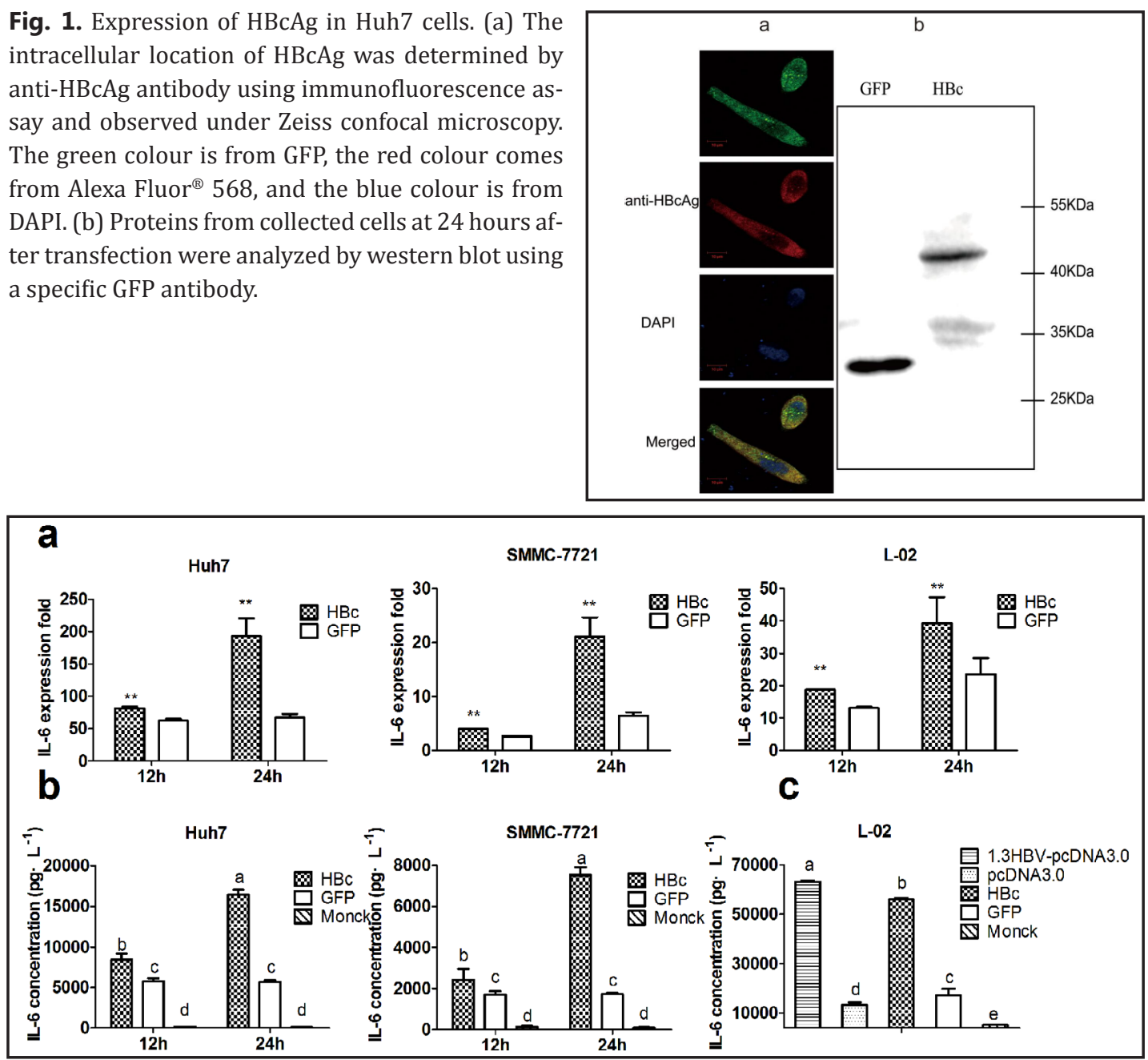

Fig. 2. IL-6 expression at mRNA and protein levels was elevated by HBcAg in hepatoma cells. (a) L-02, Huh7 and SMMC-7721 cells were transfected by HBcAg-GFP and GFP plasmids, samples were collected at 12 hours and 24 hours after transfection. The IL- 6 mRNA was detected by qRT-PCR, and the data are shown as ratios of HBcAg-GFP group or GFP group to mock group. Results are presented as mean \pm SME of triplicate experiments and analyzed by independent $t$-test. ${ }^{* *} p<0.01$. (b and c) Samples were collected at 24 hours in L-02 cells, at 12 hours and 24 hours in Huh7 cells and SMMC-7721 cells after transfection, to detected secreted IL-6 protein by ELISA. Results are presented as mean \pm SME of triplicate experiments and analyzed by one-way ANOVA (LSD). The different letters above the bars indicates significant difference $(p<0.05)$ among groups. 
Fig. 3. HBcAg upregulated the phosphorylation of p38 and ERK1/2. (a) L-02 cells, Huh7 and SMMC-7721 cells were collected at 24 hours after transfection with HBcAg-GFP or GFP plasmids. Phosphorylation of p38 and ERK1/2 was determined using specific antibodies by western blot. ( $b$ and c) The relative levels of targets proteins to GAPDH were analyzed by ImageJ software. Results are presented as mean \pm SME of triplicate experiments and analyzed by independent t-test. ${ }^{* *} p<0.01,{ }^{*} p<0.05$.

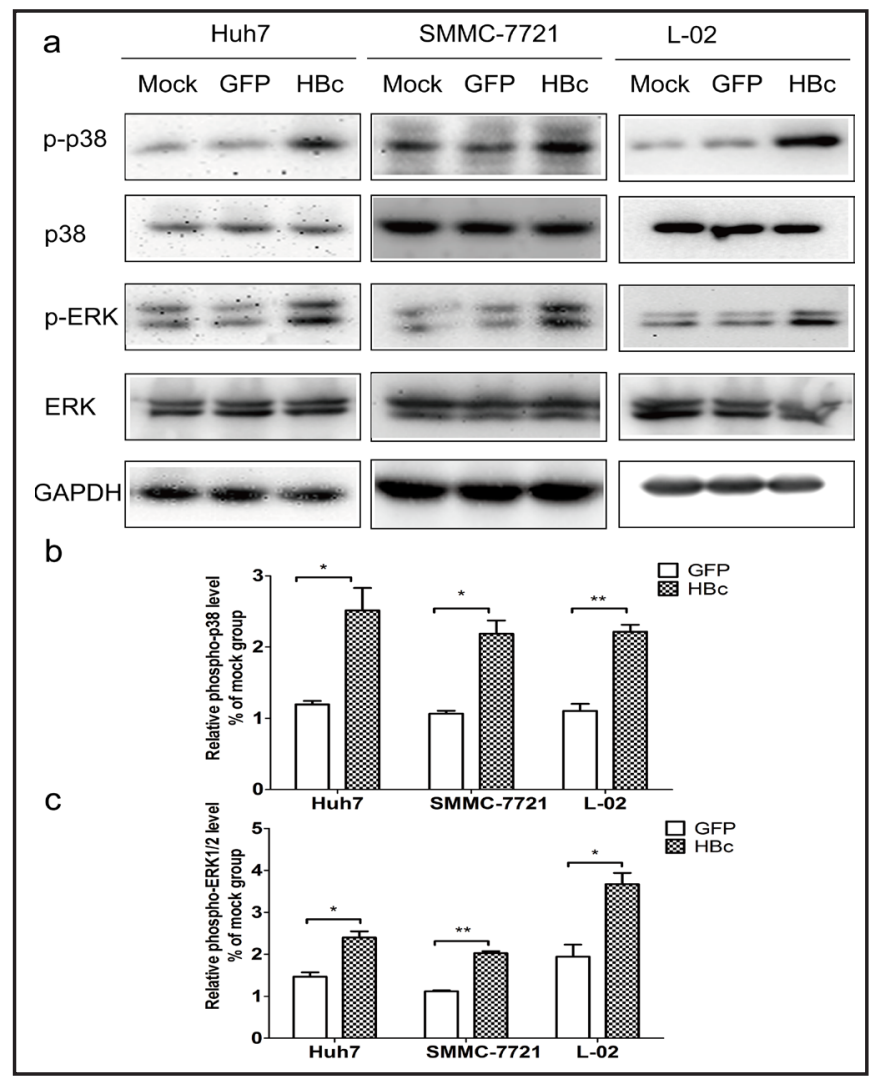

Fig. 4. HBcAg activated NF- $\kappa B$. L-02 cells, Huh7 cells and SMMC-7721 cells were collected at 24 hours after transfection with HBcAg-GFP or GFP plasmids. ( $\mathrm{a}$ and $\mathrm{b}$ ) The degradation of I $\mathrm{K}-\mathrm{B}$ was detected by western blot, and the relative levels of I $-\mathrm{B}$ to GAPDH were analyzed by Image software followed by independent $t$-test. ${ }^{*} p<0.05$. (c) The nucleus-location of p65 subunit was determined by immunofluorescence assay and observed under Zeiss confocal microscopy. The green colour is from GFP, the red colour comes from Alexa Fluor ${ }^{\circledR}$ 568 , and the blue colour is from DAPI.

regulation of the phosphorylation of p38, ERK1 and ERK2 was detected at 24 hours after transfection, although there was no significant change in the total protein levels of p38, ERK1 and ERK2 (Fig. 3).

\section{$N F-\kappa B$ was activated for $I L-6$ expression by $\mathrm{HBCAg}$}

Relative levels of NF- $\kappa B$ components were investigated upon $\mathrm{HBcAg}$-stimulated IL-6 production. Notable degradation of I $\kappa-B$ (Fig. 4 ( $a$ and b) and translocation of p65 subunit from the cytoplasm to nucleus in SMM-C7721, Huh7 and L-02 cells (Fig. 4(c)) were detected.

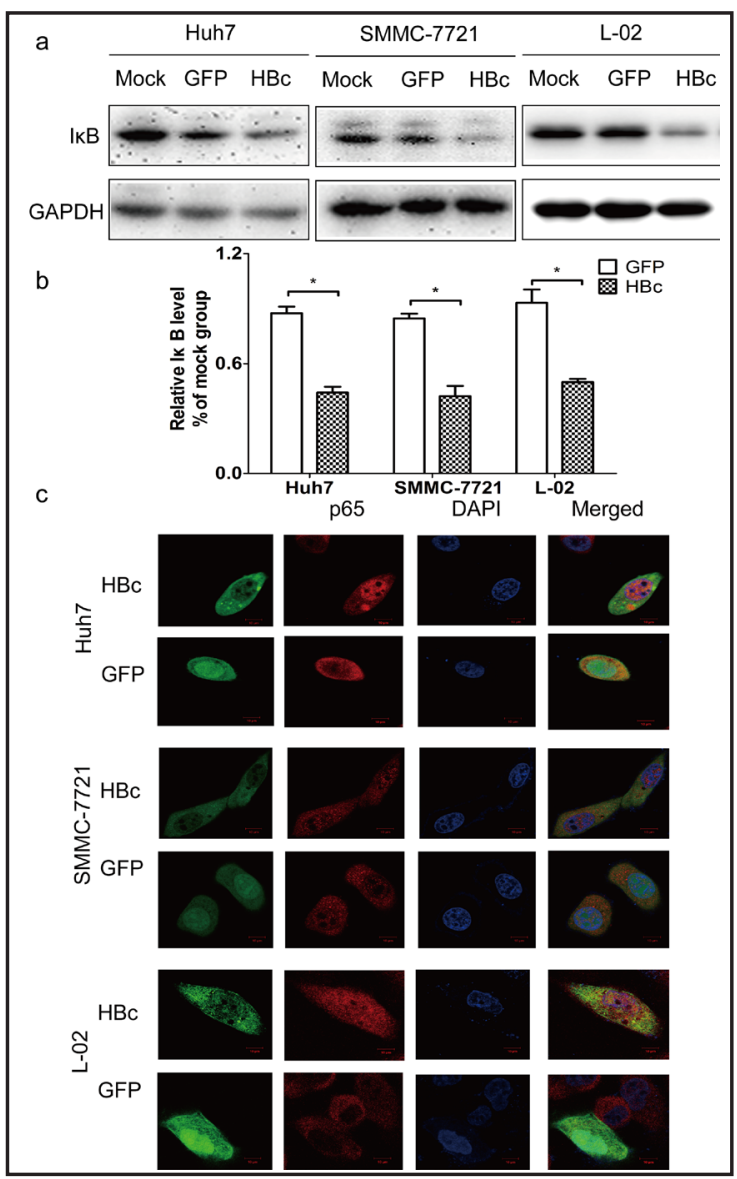




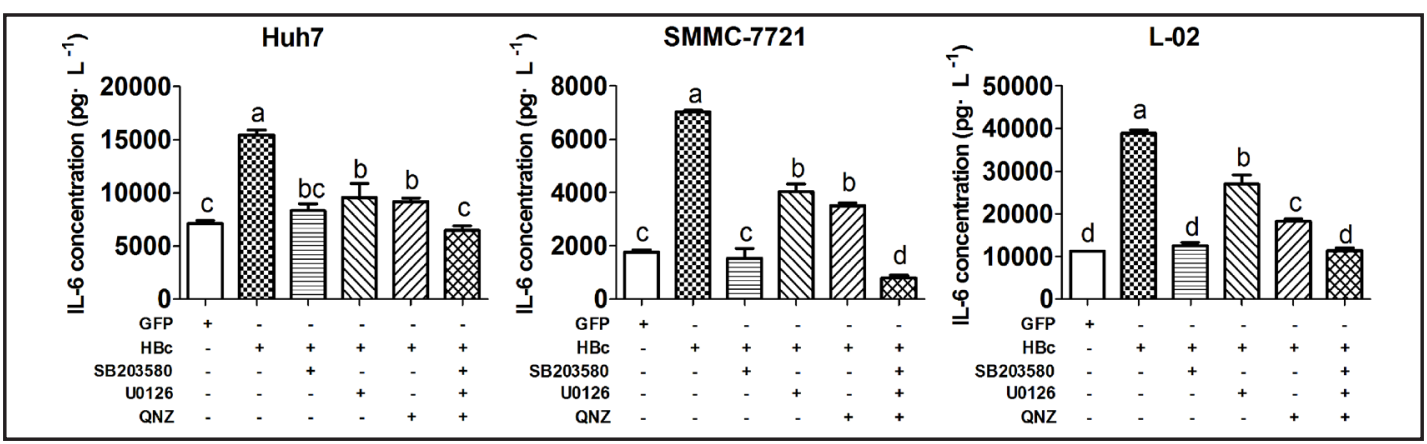

Fig. 5. Activation of p38, ERK1/2 and NF- $\kappa B$ pathways was required for HBcAg-induced IL-6 production. L-02 cells, Huh7 cells and SMMC-7721 cells were transfected with HBcAg-GFP or GFP plasmids for 12 hours, the supernatant were replaced, and the cells were washed three times and treated with $20 \mu \mathrm{M}$ SB203580, $15 \mu \mathrm{M}$ U0126 and 10 $\mu \mathrm{M}$ QNZ individually or mixedly for another 12 hours, then the secreted IL- 6 protein was detected by ELISA. The differences among groups were analyzed by one-way ANOVA (LSD). The different letters above the bars indicates significant difference $(p<0.05)$ among treatments.

\section{p38, ERK and NF- $\kappa B$ were required for HBcAg-stimulated IL-6 production}

In order to confirm the requirement of p38, ERK and NF- $\mathrm{B}$ for HBcAg-induced IL-6 expression, cells were transfected with HBcAg and treated with the p38 inhibitor SB03580, the MEK1/2 inhibitor U0126 or the NF- $\mathrm{BB}$ inhibitor QNZ to determine IL-6 expression. HBcAg-stimulated secretion of IL- 6 was significantly suppressed. The maximal suppression of IL- 6 secretion occurred in cells treated with a combination of MAPKs and NF- $\kappa B$ inhibitors (Fig. 5).

\section{Discussion}

In this study, we used a hepatic cell line and two hepatoma cell lines to study the possible link between HBcAg and IL-6 production. IL-6 expression and secretion were significantly elevated after cells were transfected with the HBcAg expression vector. The elevated IL-6 expression was accompanied by activated p38/ERKs, MEK and NF- $\kappa B$ pathways. The molecular link between the elevation of IL- 6 expression and activation of the three pathways were further suggested by individual or mixed pathway inhibitors.

$\mathrm{HBcAg}$, which is composed of 183 residues with a $21 \mathrm{kDa}$ molecular weight, is not only required for productive HBV lifecycle, but also elicit diverse responses from the host cells, due to its potent immunogenicity [4, 5, 30-34]. The strong immunogenicity of HBcAg was suggested by the stimulation of TNF- $\alpha$ production in IHLs [5], increase of TNF- $\alpha$, IL-12p40 and IL-6 expression in human THP-1 macrophages [35], and induction of IL-10, IL-17A, IL22, IL-23, IL-6 and IL-18 production in PBMCs [3, 36, 37], when HBcAg was exposed to those cells. Predominant cytoplasmic HBcAg was associated with liver injury in CHB patients [7, 8], but its exact mechnisms remain to be established. As reported, the expression of HBcAg upregulated the expression of hFGL2 through promoting the translocation of c-Est2 to the nucleus in HepG2 cells [9], while hFGL2 was possibly associated with pathogenesis of human fulminant viral hepatitis and severe CHB [10]. In this study, we expressed a GFP-tagged HBcAg fusion protein in hepatic and hepatoma cells, to mimic intracellular HBcAg in HBVinfected cells [38], to probe for possible effect on the production of $I L-6$ at both mRNA and protein levels. IL-6 is known for proinflammatory function. The elevation of IL-6 expression in response to $\mathrm{HBcAg}$, as shown in this study, provided a potential molecular link between predominant cytoplasmic HBcAg and severe liver injury, suggesting that HBcAg can increase IL- 6 production under certain circumstances, which play roles in the pathogenesis of hepatic diseases.

Previous studies have reported several signal pathways that can be regulated by HBcAg. In the presence of extracellular $\mathrm{HBcAg}$, the NF- $\mathrm{KB}$, ERK and p38 MAPK pathways were 
activated, which led to production of proinflammatory and regulatory cytokines in human monocytic THP-1 macrophages [35]. The ERK, JNK and phosphatidylinositol 3-kinase $(\mathrm{PI} 3 \mathrm{~K}) /$ protein kinase $\mathrm{B}(\mathrm{Akt})$ pathways were stimulated to induce the upregulation of the expression of PD-1 in CD4+ $\mathrm{T}$ cells [4]. In this study, p38, ERK and NF- $\kappa \mathrm{B}$ pathways were activated by the predominant cytoplasmic expression of HBcAg in transfected cells. The p38, ERK and NF- $\mathrm{BB}$ were all associated with sustained inflammation [39]. There was a significantly greater cytoplasmic HBcAg expression in hepatic cells from patients with chronic persistent hepatitis and chronic active hepatitis [7]. Our findings implicate a possible link between predominant cytoplasmic HBcAg and sustained hepatic inflammation through p38, ERK and NF- $\kappa$ B pathways. ERK1/2 pathway also contributes to cell proliferation [40], while pro-proliferation function of HBcAg has been observed. HBcAg enhances the production of human telomerase reverse transcriptase (hTERT) to promote the proliferation of HepG2 [30]. An investigation of $\mathrm{HBcAg}$ expression in liver tissue revealed predominant cytoplasmic HBcAg associated with higher levels of proliferating cell nuclear antigen (PCNA) [8]. Besides, IL-6 was also reported to be involved in liver regeneration [13, 41]. Taken together, HBcAg might play multiple roles in the progress of HBV-related disease.

In addition, other HBV proteins activated cellular signal pathways. HBx, a regulatory protein, can stimulate multiple host pathways including p38, ERK, JNK and NF- $\kappa B[20,42$, 43]. Large surface protein activated p38 and NF- $\mathrm{BB}[44,45]$, while C-terminally truncated middle surface protein activated ERK2 [46], NF- $\mathrm{KB}$ and other pathways [47]. It seems that HBV viral proteins exert a collective effect on cellular gene expression and regulatory pathways.

The liver is composed of several types of cells, in chronic active and persistent hepatitis patients, the hepatic local production of IL- 6 was observed in sinusoidal endothelial cells, necrotic areas of hepatocytes, Kupffer cells and infiltrating mononuclear cells [48]. While in vitro, HcPCs, HSCs and hepatic carcinoma-associated fibroblasts(CAFs) produce IL-6 during hepatocarcinogenesis $[16,17,49]$, sinusoidal endothelial cells and Kupffer cells secrete IL-6 in the presence of endotoxin [50,51], hepatocytes express IL-6 in response to HBx [18-20] and HBV middle surface proteins [52]. In this study, we revealed that HBcAg can also induce IL-6 production in parenchymal cells. It is proposed that the intrinisic innate immunity within hepatocytes cooperates with liver immune cells to resistant HBV infection, and the viral production like covalently closed circular DNA (cccDNA), pregenomic RNA (pgRNA) and viral proteins in hepatocytes, act as pathogen-associated molecular patterns (PAMPs) to initiate host immune response [53]. Recently, Norris et al. [54] found that under the stimulation of LPS, normal rat hepatocytes were directly induced to express IL-6 mRNAs and protein in vitro and in vivo. It can be speculated that hepatocytes secrect IL- 6 once infected by HBV, but it needs to be confirmed in the future and the role of hepatocytes played in hepatic pathogenesis remains to be explored.

\section{Conclusions}

Our results revealed that the expression of $\mathrm{HBcAg}$ in hepatic and hepatoma cells induce the elevated expression of IL-6, which was mediated through activating p38, ERK and NF- $\mathrm{BB}$ pathways. Our findings suggest new evidences for the theory that intracellular $\mathrm{HBcAg}$ is a viral antigen for immune-mediated liver damage, and HBV-infected parenchymal cells may produce proinflammatory cytokines that involved in pathogenesis of hepatitis B. However, the effects of HBcAg in vivo are worth to be verified in the future.

\section{Acknowledgments}

This work was supported by the State Science and Technology Projects of 12th Five Year, No. 2012ZX10002007. 


\section{Cellular Physiology Cell Physiol Biochem 2017;41:91-100

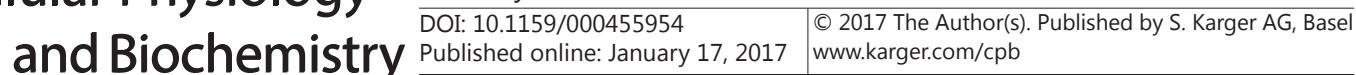

Li et al.: HBcAg Induce IL-6 Synthesis in Hepatocytes

\section{Disclosure Statement}

The authors declare no conflict of interest.

\section{References}

1 Arzumanyan A, Reis H, Feitelson MA: Pathogenic mechanisms in HBV- and HCV-associated hepatocellular carcinoma. Nat Rev Cancer 2013;13:123-135.

-2 Suhail M, Abdel-Hafiz H, Ali A, Fatima K, Damanhouri GA, Azhar E, Chaudhary AGA, Qadri I: Potential mechanisms of hepatitis B virus induced liver injury. World J Gastroenterol 2014;20:12462-12472.

-3 Li J, Wu W, Peng GP, Chen F, Bai MH, Zheng M, Chen Z: HBcAg induces interleukin-10 production, inhibiting HBcAg-specific Th17 responses in chronic hepatitis B patients. Immunol Cell Biol 2010;88:834-841.

-4 Li M, Sun XH, Zhu XJ, Jin SG, Zengl ZJ, Zhoul ZH, Yul Z, Gaol YQ: HBcAg induces PD-1 upregulation on CD4(+) $\mathrm{T}$ cells through activation of JNK, ERK and PI3K/AKT pathways in chronic hepatitis-B-infected patients. Lab Invest 2012;92:295-304.

5 Tzeng H-T, Tsai H-F, Chyuan I-T, Liao H-J, Chen C-J, Chen P-J, Hsu P-N: Tumor Necrosis Factor-Alpha Induced by Hepatitis B Virus Core Mediating the Immune Response for Hepatitis B Viral Clearance in Mice Model. PLoS one 2014;9:e103008.

6 Kawai K, Horiike N, Michitaka K, Onji M: The effects of hepatitis B virus core promoter mutations on hepatitis B core antigen distribution in hepatocytes as detected by laser-assisted microdissection. J Hepatol 2003;38:635-641.

7 Wu PC, Lau JYN, Lau TK, Lau SK, Lai CL: Relationship between intrahepatic expression of hepatitis B viral antigens and histology in Chinese patients with chronic hepatitis B virus infection. Am J Clin Pathol 1993;100:648-653.

$\checkmark 8$ Chu CM, Yeh CT, Sheen IS, Liaw YF: Subcellular localization of hepatitis B core antigen in relation to hepatocyte regeneration in chronic hepatitis B. Gastroenterology 1995;109:1926-1932.

-9 Han M, Yan W, Guo W, Xi D, Zhou Y, Li W, Gao S, Liu M, Levy G, Luo X: Hepatitis B virus-induced hFGL2 transcription is dependent on c-Ets-2 and MAPK signal pathway. J Biol Chem 2008;283:32715-32729.

10 Levy GA, Liu M, Ding J, Yuwaraj S, Leibowitz J, Marsden PA, Ning Q Kovalinka A, Phillips MJ: Molecular and functional analysis of the human prothrombinase gene (HFGL2) and its role in viral hepatitis. Am J Pathol 2000;156:1217-1225.

11 Ohishi W, Cologne JB, Fujiwara S, Suzuki G, Hayashi T, Niwa Y, Akahoshi M, Ueda K, Tsuge M, Chayama K: Serum interleukin-6 associated with hepatocellular carcinoma risk: A nested case-control study. Int J Cancer 2014;134:154-163.

$\$ 12$ Taniguchi K, Karin M: IL-6 and related cytokines as the critical lynchpins between inflammation and cancer. Semin Immunol 2014;26:54-74.

13 Xia CX, Liu YN, Chen Z, Zheng M: Involvement of Interleukin 6 in Hepatitis B Viral Infection. Cellular Physiol Biochem 2015;37:677-686.

14 Sugimoto Y, Wakai K, Nakagawa H, Suma S, Sasakabe T, Sakamoto T, Takashima N, Suzuki S, Ogawa S, Ohnaka K, Kuriyama N, Arisawa K, Mikami H, Kubo M, Hosono S, Hamajima N, Tanaka H, Grp JMS: Associations between polymorphisms of interleukin- 6 and related cytokine genes and serum liver damage markers: a cross-sectional study in the Japan Multi-Institutional Collaborative Cohort (J-MICC) Study. Gene 2015;557:158-162.

15 Jang JW, Oh BS, Kwon JH, You CR, Chung KW, Kay CS, Jung HS: Serum interleukin-6 and C-reactive protein as a prognostic indicator in hepatocellular carcinoma. Cytokine 2012;60:686-693.

16 He G, Dhar D, Nakagawa H, Font-Burgada J, Ogata H, Jiang Y, Shalapour S, Seki E, Yost SE, Jepsen K, Frazer KA, Harismendy O, Hatziapostolou M, Iliopoulos D, Suetsugu A, Hoffman RM, Tateishi R, Koike K, Karin M: Identification of Liver Cancer Progenitors Whose Malignant Progression Depends on Autocrine IL-6 Signaling. Cell 2013;155:384-396.

17 Yoshimoto S, Loo TM, Atarashi K, Kanda H, Sato S, Oyadomari S, Iwakura Y, Oshima K, Morita H, Hattori M, Honda K, Ishikawa Y, Hara E, Ohtani N: Obesity-induced gut microbial metabolite promotes liver cancer through senescence secretome. Nature 2013;499:97-101. 


\section{Cellular Physiology Cell Physiol Biochem 2017;41:91-100 \begin{tabular}{l|l|l} 
and Biochemistry $10.1159 / 000455954$ & $\begin{array}{l}\text { C } 2017 \text { The Author(s). Published by S. Karger AG, Basel } \\
\text { www.karger.com/cpb }\end{array}$ \\
\hline
\end{tabular}}

Li et al.: HBcAg Induce IL-6 Synthesis in Hepatocytes

18 Lee Y, Park US, Choi I, Yoon SK, Park YM, Lee YI: Human interleukin 6 gene is activated by hepatitis B virus-X protein in human hepatoma cells. Clin Cancer Res 1998;4:1711-1717.

19 Kim JS, Rho BY, Lee TH, Lee JM, Kim SJ, Park JH: The interaction of hepatitis B virus X protein and protein phosphatase type $2 \mathrm{C}$ alpha and its effect on IL-6. Biochem Biophys Res Commun 2006;351:253-258.

20 Xiang W-Q Feng W-F, Ke W, Sun Z, Chen Z, Liu W: Hepatitis B virus X protein stimulates IL-6 expression in hepatocytes via a MyD88-dependent pathway. J Hepatol 2011;54:26-33.

-21 Davies SP, Reddy H, Caivano M, Cohen P: Specificity and mechanism of action of some commonly used protein kinase inhibitors. Biochem J 2000;351:95-105.

-22 Cuenda A, Rouse J, Doza YN, Meier R, Cohen P, Gallagher TF, Young PR, Lee JC: SB 203580 is a specific inhibitor of a MAP kinase homologue which is stimulated by cellular stresses and interleukin-1. FEBS Lett 1995;364:229-233.

23 Eyers PA, Craxton M, Morricel N, Cohen P, Goedert M: Conversion of SB 203580-insensitive MAP kinase family members to drug-sensitive forms by a single amino-acid substitution. Chem Biol 1998;5:321-328.

24 Gum RJ, McLaughlin MM, Kumar S, Wang Z, Bower MJ, Lee JC, Adams JL, Livi GP, Goldsmith EJ, Young PR: Acquisition of sensitivity of stress-activated protein kinases to the p38 inhibitor, SB 203580, by alteration of one or more amino acids within the ATP binding pocket. J Biol Chem 1998;273:15605-15610.

-25 Kennedy RA, Kemp TJ, Sugden PH, Clerk A: Using U0126 to dissect the role of the extracellular signalregulated kinase $1 / 2($ ERK1/2) cascade in the regulation of gene expression by endothelin-1 in cardiac myocytes. J Mol Cell Cardiol 2006;41:236-247.

-26 Beck GR, Knecht N: Osteopontin regulation by inorganic phosphate is ERK1/2-, protein kinase C-, and proteasome-dependent. J Biol Chem 2003;278:41921-41929.

27 Tobe M, Isobe Y, Tomizawa H, Nagasaki T, Takahashi H, Hayashi H: A novel structural class of potent inhibitors of NF-kappa B activation: Structure-activity relationships and biological effects of 6-aminoquinazoline derivatives. Bioorg Med Chem 2003;11:3869-3878.

28 Choi S, Kim JH, Roh EJ, Ko MJ, Jung JE, Kim HJ: Nuclear factor-kappa B activated by capacitative Ca2+ entry enhances muscarinic receptor-mediated soluble amyloid precursor protein (sAPP alpha) release in SHSY5Y cells. J Biol Chem 2006;281:12722-12728.

29 Karki P, Johnson J, Son D-S, Aschner M, Lee E: Transcriptional Regulation of Human Transforming Growth Factor- $\alpha$ in Astrocytes. Mol Neurobiol 2016;1-13.

-30 Gai XX, Zhao PQ, Pan YF, Shan HX, Yue XT, Du J, Zhang ZY, Liu P, Ma HX, Guo M, Yang XY, Sun WS, Gao LF, Ma $\mathrm{CH}$, Liang XH: Hepatitis B virus core protein enhances human telomerase reverse transcriptase expression and hepatocellular carcinoma cell proliferation in a c-Ets2-dependent manner. Int J Biochem Cell Biol 2013;45:1174-1185.

-31 Liu W, Lin Y-T, Yan X-L, Ding Y-L, Wu Y-L, Chen W-N, Lin X: Hepatitis B virus core protein inhibits Fasmediated apoptosis of hepatoma cells via regulation of $\mathrm{mFas} / \mathrm{FasL}$ and sFas expression. FASEB J 2015;29:1113-1123.

32 Du J, Liang X, Liu Y, Qu Z, Gao L, Han L, Liu S, Cui M, Shi Y, Zhang Z, Yu L, Cao L, Ma C, Zhang L, Chen Y, Sun W: Hepatitis B virus core protein inhibits TRAIL-induced apoptosis of hepatocytes by blocking DR5 expression. Cell Death Differ 2009;16:219-229.

- 33 Jia B, Guo M, Li G, Yu D, Zhang X, Lan K, Deng Q: Hepatitis B Virus Core Protein Sensitizes Hepatocytes to Tumor Necrosis Factor-Induced Apoptosis by Suppression of the Phosphorylation of Mitogen-Activated Protein Kinase Kinase 7. J Virol 2015;89:2041-2051.

34 Ou JH: Molecular biology of hepatitis B virus e antigen. J Gastroenterol Hepatol 1997;12:S178-S187.

-35 Cooper A, Tal G, Lider O, Shaul Y: Cytokine induction by the hepatitis B virus capsid in macrophages is facilitated by membrane heparan sulfate and involves TLR2. J Immunol 2005;175:3165-3176.

-36 Manigold T, Böcker U, Chen J, Gundt J, Traber P, Singer MV, Rossol S: Hepatitis B core antigen is a potent inductor of interleukin-18 in peripheral blood mononuclear cells of healthy controls and patients with hepatitis B infection. J Med Virol 2003;71:31-40.

37 Whitten TM, Quets AT, Schloemer RH: Identification of the hepatitis B virus factor that inhibits expression of the beta interferon gene. J Virol 1991;65:4699-4704.

-38 Dienes HP, Gerlich WH, Worsdorfer M, Gerken G, Bianchi L, Hess G, Zumbuschenfelde KHM: Hepatic expression patterns of the large and middle hepatitis-B virus surface-proteins in viremic and nonviremic chronic hepatitis-B. Gastroenterology 1990;98:1017-1023. 


\section{Cellular Physiology Cell Physiol Biochem 2017;41:91-100 \begin{tabular}{l|l} 
DOI: 10.1159/000455954 & $\begin{array}{l}\text { O 2017 The Author(s). Published by S. Karger AG, Basel } \\
\text { www.karger.com/cpb }\end{array}$ \\
\hline
\end{tabular}}

Li et al.: HBCAg Induce IL-6 Synthesis in Hepatocytes

39 Lin J, Wu J-F, Zhang Q, Zhang H-W, Cao G-W: Virus-related liver cirrhosis: Molecular basis and therapeutic options. World J Gastroenterol 2014;20:6457-6469.

-40 Chung JH, Kang S, Varani J, Lin J, Fisher GJ, Voorhees JJ: Decreased extracellular-signal-regulated kinase and increased stress-activated MAP kinase activities in aged human skin in vivo. J Invest Dermatol 2000;115:177-182.

41 Obayashi Y, Arisaka H, Yoshida S, Mori M, Takahashi M: Proline protects liver from D-galactosamine hepatitis by activating the IL-6/STAT3 survival signaling pathway. Amino Acids 2012;43:2371-2380.

42 Ma JW, Sun TC, Park S, Shen GX, Liu JW: The role of hepatitis B virus X protein is related to its differential intracellular localization. Acta Biochim Biophys Sin (Shanghai) 2011;43:583-588.

-43 He P, Zhang B, Liu D, Bian X, Li D, Wang Y, Sun G, Zhou G: Hepatitis B Virus X Protein Modulates Apoptosis in NRK-52E Cells and Activates Fas/FasL Through the MLK3-MKK7-JNK3 Signaling Pathway. Cell Physiol Biochem 2016;39:1433-1443.

44 Hung JH, Su IJ, Lei HY, Wang HC, Lin WC, Chang WT, Huang WY, Chang WC, Chang YS, Chen CC, Lai MD: Endoplasmic reticulum stress stimulates the expression of cyclooxygenase-2 through activation of NFkappa B and pp38 mitogen-activated protein kinase. J Biol Chem 2004;279:46384-46392.

45 Hildt E, Saher G, Bruss V, Hofschneider PH: The hepatitis B virus large surface protein (LHBs) is a transcriptional activator. Virology 1996;225:235-239.

46 Liang X, Du J, Liu Y, Cui M, Ma C, Han L, Qu Z, Zhang Z, Sun Z, Zhang L: The hepatitis B virus protein MHBs (t) sensitizes hepatoma cells to TRAIL-induced apoptosis through ERK2. Apoptosis 2007;12:1827-1836.

-47 Caselmann WH, Renner M, Schluter V, Hofschneider PH, Koshy R, Meyer M: The hepatitis B virus MHBs(t167) protein is a pleiotropic transactivator mediating its effect via ubiquitous cellular transcription factors. J Gen Virol 1997;78:1487-1495.

48 Kakumu S, Fukatsu A, Shinagawa T, Kurokawa S, Kusakabe A: Localization of intrahepatic Interleukin-6 in patients with acute and chronic liver-disease. J Clin Pathol 1992;45:408-411.

49 Cheng JT, Deng YN, Yi HM, Wang GY, Fu BS, Chen WJ, Liu W, Tai Y, Peng YW, Zhang Q: Hepatic carcinomaassociated fibroblasts induce IDO-producing regulatory dendritic cells through IL-6-mediated STAT3 activation. Oncogenesis 2016;5: e198.

-50 Ishimaru M, Yusuke N, Tsukimoto M, Harada H, Takenouchi T, Kitani H, Kojima S: Purinergic signaling via P2Y receptors up-mediates IL-6 production by liver macrophages/Kupffer cells. J Toxicol Sci 2014;39:413 423.

-51 Knolle PA, Loser E, Protzer U, Duchmann R, Schmitt E, ZumBuschenfelde KHM, RoseJohn S, Gerken G: Regulation of endotoxin-induced IL-6 production in liver sinusoidal endothelial cells and Kupffer cells by IL-10. Clin Exp Immunol 1997;107:555-561.

-52 Li YX, Ren YL, Fu HJ, Zou L, Yang Y, Chen Z: Hepatitis B Virus Middle Protein Enhances IL-6 Production via p38 MAPK/NF-kappa B Pathways in an ER Stress-Dependent Manner. PLoS One 2016;11:e0159089.

-53 Yi ZG, Chen JL, Kozlowski M, Yuan ZH: Innate detection of hepatitis B and C virus and viral inhibition of the response. Cell Microbiol 2015;17:1295-1303.

-54 Norris CA, He M, Kang LI, Ding MQ Radder JE, Haynes MM, Yang Y, Paranjpe S, Bowen WC, Orr A, Michalopoulos GK, Stolz DB, Mars WM: Synthesis of IL-6 by Hepatocytes Is a Normal Response to Common Hepatic Stimuli. PLoS One 2014;9:e96053. 